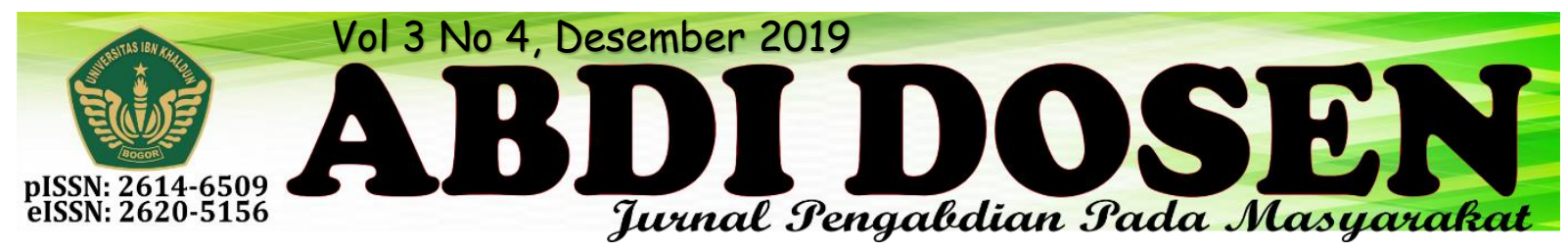

\title{
MEWUJUDKAN STABILITAS EKONOMI, PENDIDIKAN DAN KESEHATAN DALAM RANGKA PEMBERDAYAAN MASYARAKAT DI DESA CIARUTEUN ILIR
}

\author{
Mukhtar $^{1}$, Intan Rahma Utami, Durriyah Najibah Imtinan ${ }^{2}$ \\ mukhtar@fai.uika-bogor.ac.id \\ Fakultas Agama Islam Universitas Ibn Khaldun', Mahasiswa KKN Kelompok 22 Tahun $2018^{2}$
}

\begin{abstract}
ABSTRAK
Kuliah Kerja Nyata $(\mathrm{KKN})$ merupakan bentuk kegiatan pengabdian kepada masyarakat oleh mahasiswa dengan pendekatan lintas keilmuan dan sektoral pada waktu dan daerah tertentu. Kegiatan tersebut bertujuan untuk memahami permasalahan yang terjadi di masyarakat. Permasalahan tersebut terbagi ke dalam beberap sektor, seperti ekonomi, pendidikan dan kesehatan. Ketiga aspek tersebut sangat berkaitan dalam proses pemberdayaan masyarakat. Terlebih jika masyarakatnya memiliki potensi yang baik dalam ketiga aspek tersebut. Salah satu desa yang memiliki potensi yang baik dalam bidang ekonomi dan kesehatan adalah Desa Ciaruteun Ilir Kecamatan Cibungbulang Kabupaten Bogor. Masyarakat di desa tersebut mayoritas bekerja sebagai petani kebun, karena sebagian besar wilayahnya ditanami berbagai macam sayur-sayuran serta tanaman hijau lainnya. Jika perkebunan tersebut dikelola dengan sistem yang sangat baik maka tidak menutup kemungkinan potensi ekonomi di desa tersebut akan berkembang sangat baik pula. Pengelolaan sistem ekonomi juga harus didukung dengan pemahaman masyarakatnya, maka dari itu aspek pendidikan pun perlu mendapatkan perhatian agar masyarakat desa tersebut dapat belajar serta memahami dengan baik mengenai sistem perekonomian yang juga didukung dengan pemahaman kesehatan bagi para petani di desa tersebut.
\end{abstract}

\section{Kata Kunci : Stabilitas Ekonomi, Pendidikan, Kesehatan, Pemberdayaan}

\section{PENDAHULUAN}

Desa Ciaruteun ilir kecamatan Cibungbulang Bogor merupakan salah satu tempat yang di pilih dan ditunjuk LPPM untuk menjadi tempat pelaksanaan kuliah kerja nyata yang bertemakan tematik terintegrasi. Anggota posko 22 berjumlah 11 orang yang berasal dari fakultas dan jurusan yang berbeda - beda. Setelah melihat hasil survey dan menganalisis daerah maka Tim KKN Posko 22 memilih untuk menyusun program yang mencakup empat pilar utama yaitu, Ekonomi,
Pendidikan dan Kesehatan. Kondisi masyarakat di Desa Ciaruteun Ilir cukup produktif dibidang pertanian dan di luar bidang pertanian seperti kegiatan pengajian rutin dan posyandu. Kurangnya kepedulian masyarakat di Desa Ciaruteun ilir dalam bidang pendidikan berdampak

pada keinginan dan antusiasme warga terhadap pendidikan itu sendiri. Dalam bidang ekonomi di Desa Ciaruteun Ilir belum cukup maju, karena hampir $80 \%$ masyarakatnya berprofesi sebagai petani, 
seperti petani bayam, kangkung, kemangi dan sebagainya. Dalam hal pemasarannya masih sebatas memasok ke pasar-pasar di wilayah kota dan kabupaten bogor. Dalam bidang kesehatan kesadaran masyarakat untuk berperilaku hidup sehat dan bersih sejak dini sudah cukup baik. Dalam bidang lingkungan tidak tersedianya tempat sampah sehingga warga yang berada di desa sebagian membuang sampah di sembarang tempat, seperti di kali kecil yang pada akhirnya menyumbat aliran kali kecil tersebut.

\section{Keadaan Geografis}

Desa Ciaruteun Ilir luas wilayahnya $360 \mathrm{Ha}$, terdiri dari $10 \mathrm{RW} 35 \mathrm{RT}$ dan 4 Dusun. Yaitu Dusun I, II, III dan Dusun IV. Jarak dari Desa Ciaruteun Ilir ke ibu kota

\section{METODOLOGI}

\section{Tahap Pelaksanaan}

Metode yang dimaksud disini yaitu metode pelaksanaan $\mathrm{KKN}$ yang tidak lain merupakan tindakan dari penelitian sebagai langkah awal melaksanakan KKN karena sebelum terjun kelapangan tentu saja perlu dilakukan beberapa penelitian untuk perumusan masalah dan penemuan solusi.

Adapun metode- metode yang digunakan dalam pelaksanaan $\mathrm{KKN}$ Tematik Terintegrasi tersebut diantaranya yaitu metode etnografis dan studi kasus.

\section{Partisipasi Masyarakat}

Partisipasi masyarakat yang dapat dilakukan dalam kegiatan ini adalah sebagai berikut:
Kecamatan Cibungbulang $6 \mathrm{Km}$, jarak ke ibu kota Kabupaten Bogor $21 \mathrm{Km}$, jarak ke ibu kota Provinsi di Bandung $161 \mathrm{Km}$ dan jarak ke ibu kota Negara di Jakarta $83 \mathrm{Km}$.

\section{Batas Wilayah}

\begin{tabular}{|c|l|c|}
\hline No & Keterangan & Berbatasan \\
\hline 1 & Utara & Cidokom \\
\hline 2 & Selatan & Leuweungkolot \\
\hline 3 & Barat & Cijujung \\
\hline 4 & Timur & Ciampea \\
\hline
\end{tabular}

Kondisi Masyarakat

\begin{tabular}{|c|l|c|c|c|}
\hline No & Tahun & $\begin{array}{c}\text { Laki- } \\
\text { Laki }\end{array}$ & Perempuan & $\begin{array}{c}\text { Jumlah } \\
\text { Penduduk }\end{array}$ \\
\hline 1 & 2013 & 5.520 & 5.344 & 10.684 \\
\hline 2 & 2014 & 5.744 & 5.368 & 11.112 \\
\hline 3 & 2015 & 5.873 & 5.426 & 11.299 \\
\hline
\end{tabular}

1. Mempersiapkan masyarakat untuk mengikuti kegiatan program kerja yang dilaksanakan.

2. Mempersiapkan tempat untuk melaksanakan program kerja.

3. Ikut membantu menyiapkan konsumsi pada pelaksanaan program kerja.

\section{Langkah Evaluasi}

Evaluasi yang akan dilakukan terdiri dari:

1. Evaluasi proses

2. Evaluasi hasil

3. Evaluasi dampak diarahkan untuk melihat efektivitas program kerja yang telahterlaksana. 


\section{HASIL PROGRAM}

Dari bidang Pendidikan, program yang telah dicapai:
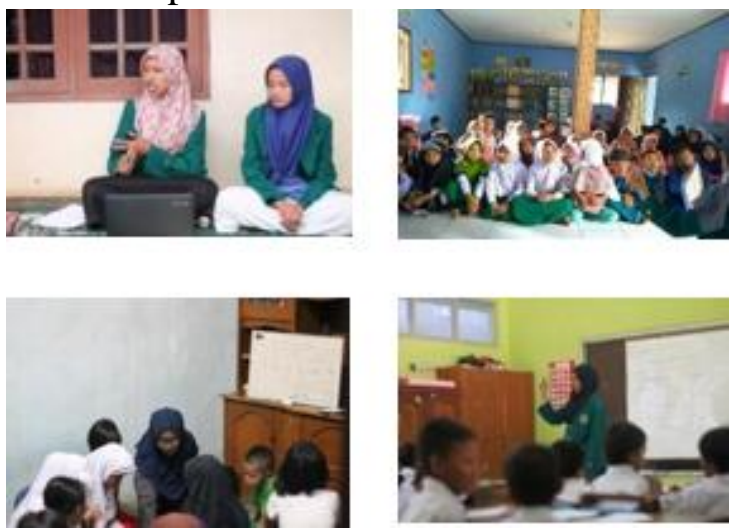

a. Bimbingan belajar yang dilaksanakan di posko KKN 22

b. Kegiatan mengajar di SDN Ciaruteun Ilir 02

c. Kegiatan mengajar di TPA Bani Salif

d. Penyuluhan pendidikan keluarga

Dari bidang Ekonomi, program yang telah dicapai:
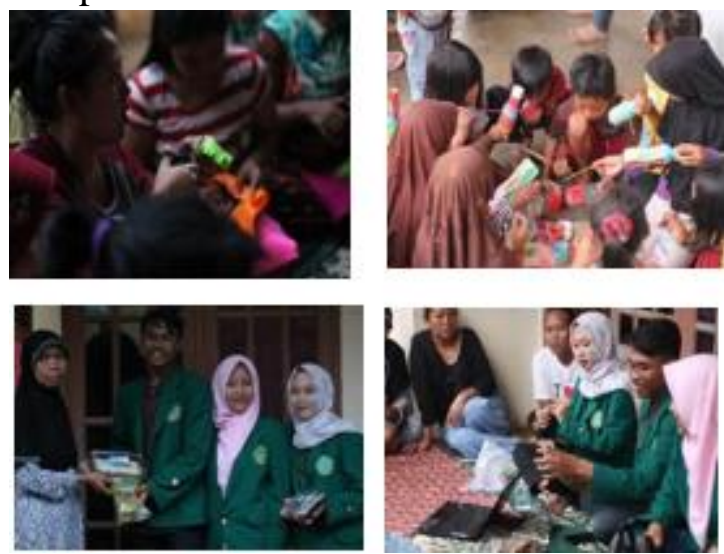

a. Penyuluhan budaya menabung

b. Ekonomi kreatif, membuat kerajinan dari kain flannel

\section{KESIMPULAN}

Program kelompok 22 KKN terintegrasi 2018 terlaksana dengan baik dan memberi dampak positif bagi masyarakat yang terdiri dari 4 bidang program kerja, yaitu bidang pendidikan, bidang ekonomi, bidang, kesehatan dan sosial kemasyarakatan :

a. Bidang Pendidikan Permasalahan: c. Ekonomi kreatif, membuat kripik bayam dan brownis bayam

d. Penyuluhan Kewirausahaan (wirausaha dan kewirausahaan islami)

Dari bidang Kesehatan, program yang telah dicapai:
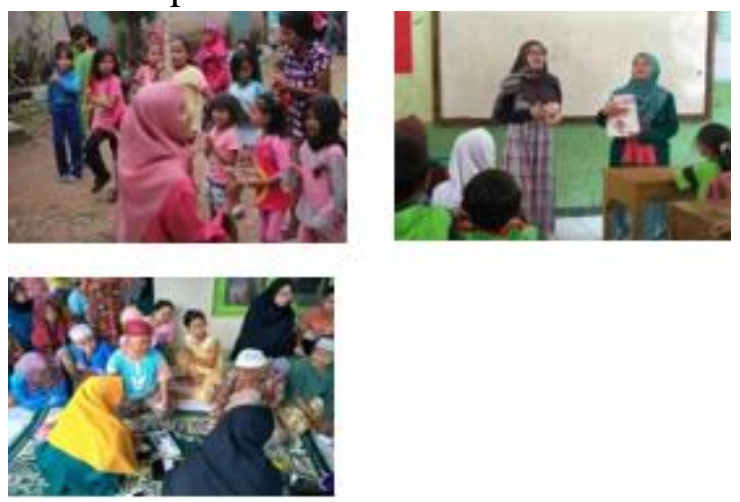

a. Senam kreasi

b. Penyuluhan sikat gigi

c. Cek kesehatan

Dari bidang Sosial Kemasyarakatan, program yang telah dicapai:
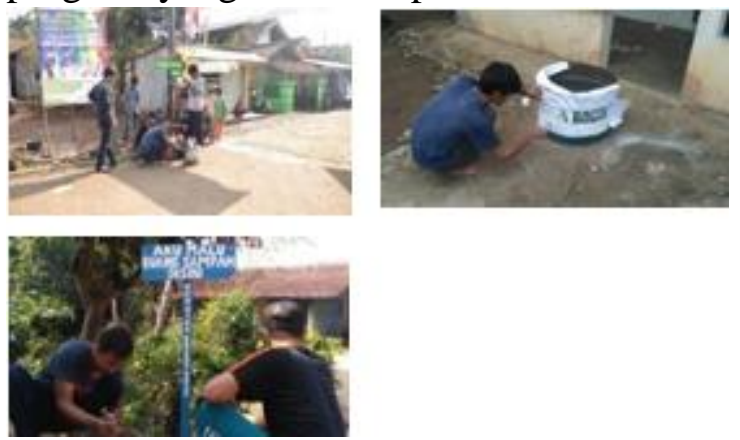

a. Pembuatan plang penunjuk jalan

b. Pembuatan tong sampah

c. Pembuatan plang kebersihan

1. Tenaga pengajar atau guru di sekolah tersebut tidak pernah menggunakan metode yang bervariasi dalam mengajar sehingga siswa kesulitan dalam memahami materi pelajaran.

2. Sulit dalam mengatur jadwal mengajar. 
3. Banyak ibu-ibu yang tidak memahami apa itu Penyuluhan Parenting.

Penanggulangan :

1. Menggunakan metode pembelajaran yang variatif.

2. Membagi waktu belajar ke dalam dua sesi.

3. Menjelaskan dari awal apa itu Penyuluhan Parenting

b. Bidang Ekonomi Permasalahan :

1. Sulitnya menarik minat anak-anak dalam mendengarkan materi

2. Sulitnya mengkondusifkan anakanak dalam mengecat dan menghias celengan.

3. Kesibukan sasaran yang mayoritas sebagai petani.

4. Keterbatasan waktu untuk mengadakan pelatihan membuat kripik dan brownis bayam.

5. Keterbatasan waktu untuk mengadakan penyuluhan.

Penanggulangan :

1. Menambahkan media audio visual dalam menyampaikan informasi tentang pentingnya menabung.

2. Sasaran dibagi kedalam beberapa kelompok yang setiap kelompoknya dibimbing oleh anggota kelompok KKN 22.

3. Menyesuaikan kegiatan dengan waktu luang sasaran.

4. Memperlihatkan dan memberikan produk jadi sebagai contoh dan juga memberikan cara-cara membuatnya.

5. Memberikan materi dalam bentuk hardcopy kepada sasaran.

c. Bidang Kesehatan Permasalahan :

1. Kurangnya Partisipasi warga dalam mengikuti Senam Kreasi Kesehatan.
2. Warga yag sibuk sebagai ibu rumah tangga yang harus menyelesaikan pekerjaan rumah menjadikan acara menjadi terlambat hingga beberapa menit.

3. Kurangnya pengetahuan siswasiswi tentang gigi.

4. Tindakkan dalam menggosik gigi, siswa-siswi masih kurang memahami.

5. Jumlah siswa-siswi terlalu banyak, sehingga tidak kondusif.

6. Kondisi Hujan yang deras sehingga kegiatan berhenti sejenak.

7. Kondisi Ruangan yang sempit. Penanggulangan :

1. Untuk menarik minat warga RT 01 RW 02, 02 RW 02 RT 03 RW 03 dengan memberikan kupon hadiah.

2. Leaflet.

3. Menggunakan Gambar Gigi.

4. Patung Gigi.

5. Menggunakan Kupon agar antrian berjalan dengan baik.

6. Menambah Waktu Pelaksanaan Kegiatan.

d. Bidang Sosial Kemasyarakatan Permasalahan :

1. Kurang mengetahui letak geografis.

2. Tidak adanya petugas kebersihan sehingga sampah menumpuk.

3. Kurangnya antusias warga dalam pembuatan plang

Penanggulangan :

1. Meminta bantuan pak Rt dalam pemasangan.

2. Membakar sampah pada tong yang telah dibuat.

3. Mahasiswa dan rt setempat bekerja sama dalam pembuatan. 


\section{SARAN}

Sosialisasi mengenai KKN Tematik Terintegrasi tidak hanya kepada aparat pemerintah, namun sebaiknya oleh LPPM kepada Masyarakat yang berinteraksi langsung dengan Mahasiswa peserta KKN Tematik Terintegrasi dapat dilaksanakan sebelum penerjunan. Selain itu, perlu

\section{DAFTAR PUSTAKA}

Petunjuk Pelaksanaan KKN Tematik Terintegrasi 2018, Bogor, Universitas Ibn Khaldun.

B,Mahirah. (2017) "Evaluasi Belajar Peserta Didik (Siswa)" JURNAL IDAARAH, VOL. I, NO. 2, DESEMBER 2017

Perdana,Amelia., Halilullah, Nurmalisa, Yunisca., (2013) "Pengaruh Pelaksanaan KuliahKerja Nyata (KKN) Terhadap Keterampilan Sosial M-ahasiswa Program Studi adanya dukungan dari LPPM untuk pemantauan yang berkelanjutan mengenai KKN Tematik Terintergrasi yang telah dibentuk di Desa sasaran KKN dan beberapa program yang perlu ada tindakan berkelanjutan.

PPKN Universitas Lampung Tahun 2013". Universitas Lampung.

Purwaningrum, Pramiati, Jakarta 2016, Upaya Mengurangi Timbulan Sampah Plastik di Lingkungan

Hatma, Akbar. (2017) Tujuan dan Manfaat Kuliah Kerja Nyata. (Online) https://hatma.net/tujuan-danmanfaat-kuliah- kerja-nyata-kkn/ (Diakses 2 Oktober 2017) 